\title{
Defective apoptosis of U937 cells induced by benzyl isothiocyanate (BITC)
}

\author{
Grzegorz Stasiłojćø, Anna Nagel, Patrycja Koszałka and Jacek Jerzy Bigda \\ Department of Cell Biology and Immunology, Intercollegiate Faculty of Biotechnology UG-MUG, Medical University of Gdansk, Gdańsk, Poland
}

\begin{abstract}
Isothiocyanates' precursors (ITCs), including benzyl isothiocyanate (BITC), are considered as cancer chemopreventive agents. ITC derivatives were tested in clinical trials (NCT00005883, NCT01265953, NCT01790204) and preclinical studies aimed to inhibit tumor growth and modulation of their microenvironment. Although efficacy of ITCs was demonstrated with several leukemic cell lines, the final steps of BITC-induced apoptosis were not completely elucidated in the literature. Therefore, we focused on morphological and biochemical events occurring upon treatment of U937 leukemia cells with BITC. Micromolar concentrations of BITC induced cytotoxicity in U937 cells, with major features resembling the hallmarks of apoptosis: phosphatidylserine exposure, low mitochondrial membrane potential, and presence of PARP cleavage by caspases. Disassembly to apoptotic bodies, a final step of classic apoptosis, was not observed. While tracing the signalling pathways, our results showed increased levels of BAG-1 and PUMA proteins, but in contrast to other models of ITCs-induced apoptosis, downregulation of $\mathrm{Mcl}-1$ protein was not noticed. Additionally, BITC-induced dying U937 cells released lower levels of chemoattractants, such as IL-8 and MCP1 , when compared to cells undergoing classical apoptosis. This may disrupt clearance of cell debris by macrophages in vivo (efferocytosis), and in turn affect the inflammatory response. In summary, BITC inhibits tumor growth which makes it a good candidate for supporting cancer treatment. However, atypical apoptosis of leukemic U937 cells induced with BITC may affect the ability of phagocytes to effectively scavenge cellular debris, which poses a question of BITC effectiveness as a chemopreventive agent for leukemias.
\end{abstract}

Key words: benzyl isothiocyanate, apoptosis, U937, blebbing

Received: 22 January, 2019; revised: 29 August, 2019; accepted: 25 September, 2019; available on-line: 24 October, 2019

๑e-mail: gstasilojc@gumed.edu.pl

*Acknowledgements of Financial Support: The authors would like to acknowledge funding from the project No. N N401 196939 of the National Science Centre (2010-2012) and from the core fund of the Intercollegiate Faculty of Biotechnology project No. 538-M000B146-13 (2013).

Abbreviations: BAG-1, BCL2-associated athanogene; PUMA, p53 upregulated modulator of apoptosis; Mcl-1, myeloid cell leukemia-1; CSC, cancer stem cell; PS, phosphatidylserine; VP-16, Vepesid ${ }^{\circledast / e t o p o s i d e ; ~ D A P I, ~ 4 ', 6-D i a m i d i n e-2 '-p h e n y l i n d o l e ~ d i h y-~}$ drochloride; MMP, Mitochondrial membrane potential; TMRM, tetramethyl rhodamine methyl ester; $\mathrm{LDH}$, lactate dehydrogenase; ROCK, Rho-associated protein kinase; DAMPs, damage-associated molecular patterns

\section{INTRODUCTION}

Chemoprevention is a strategy to inhibit, delay or reverse carcinogenesis using naturally occurring or synthetic chemical agents. Chemopreventive properties are especially attributed to isothiocyanates (ITCs) (Zhou et al., 2013), the organosulfur compounds abundantly present mainly in the cruciferous vegetables (e.g., watercress, brussels sprouts, broccoli, cabbage). ITCs are the product of enzymatic activity of a plant-specific myrosinase or glucosinolates of intestinal flora (Miyoshi et al., 2012).

Over the past three decades, research has confirmed the efficacy of various ITCs against cancer in preclinical models (Rao, 2013). One of such dietary chemopreventive agents is the benzyl isothiocyanate (BITC), which exerts anti-inflammatory properties and is characterized by the ability to inhibit growth of various chemically induced tumours (Lee et al., 2009; Rao 2013) or cancer stem cells CSC (Kim \& Singh, 2015), by inducing apoptosis. BITC mediates inhiet al. bition of clonogenicity and soft-agar colony formation by breast cancer cells (Xie et al., 2017). Exposure of different cell lines to BITC promotes apoptosis with majority of its characteristic biochemical changes, e.g. caspase activation, cytochrome c release, nuclear apoptosis-inducing factor (AIF) accumulation, and $\mathrm{Bcl} 2$-associated $\mathrm{X}$ protein (Bax) translocation (Liu et al., 2013; Zhou et al., 2013). BITC is able to cause cell cycle arrest in the $\mathrm{G} 2 / \mathrm{M}$ phase, reactive oxygen species generation and glutathione depletion (Liu et al., 2013). Molecular understanding of BITC-mediated signalling networks is still not fully elucidated (Xie et al., 2017).

Apoptosis was considered as a immunologically silent process (Negroni et al., 2015), although literature data suggests that it may promote inflammatory events which potentially recruit and activate immune cells. Aberrations of apoptosis inevitably involve adverse effects. The effectiveness of disassembly of a dying cell to apoptotic bodies should be taken under consideration in terms of cancer therapy. Such disassembly is the most critical step in apoptosis-induced immune response. Inefficient clearance of dying cells causes persistent inflammation (Wickman et al., 2013), a critical component of cancer progression. Data suggest that inflammatory microenvironment may be an indispensable participant in the neoplastic process (Bakker et al., 2016).

The study presented here was designed to determine the mechanism of BITC-induced apoptosis of leukemia cells, with special emphasis on cell disassembly. Leukemia is a white blood cells cancer, with over 54000 new cases diagnosed worldwide per year, and a 5-year survival rate below 60\% (Bakker et al., 2016). We used U937 cells as a commonly utilized research model of mono- 
cytes. They were used in studies on cell death (Stasilojc et al., 2013), novel anticancer drugs' evaluation, including ITCs action (Zhou et al., 2013), as well as an in vitro assay to identify contact sensitizers (Python et al., 2007).

Apoptosis is characterized by contraction and shrinkage of cytoplasmic organelles, as well as nuclear chromatin condensation (Wickman et al., 2013; Zhou et al., 2013). Formation of membrane blebs precedes disassembly to apoptotic bodies (Rao, 2013; Zhou et al., 2013). Exposure of phosphatidylserine (PS) on the outer leaflet of cell membrane, decrease in mitochondrial membrane potential, release of cytochrome $c$ from mitochondria and activation of caspases (Fadok et al., 1992; Keum et al., 2004) are also the hallmarks of apoptosis. The most important final step of this process is efferocytosis followed by a "silent" immune response. Lack of pro-inflammatory activity towards cell debris after apoptosis is correlated with anti-inflammatory reaction of the neighbouring tumour and immune cells (Grabiec \& Hussell, 2016). Inadequate engulfment of apoptotic bodies is followed by plasma membrane rupture and release of immunogenic intracellular materials (Grabiec \& Hussell, 2016; Toda et al., 2015; Wickman et al., 2013; Zhang et al., 2018). Dysfunction of disassembly may affect the scavenging of cell remains and, indirectly, effectiveness of leukemia therapy with BITC.

Here, we report atypical morphology of BITC-treated U937 cells with significantly lower level of chemoattractants released and a decreased degree of cell disassembly to apoptotic bodies when compared to cells exposed to etoposide (VP-16), a popular anticancer chemotherapeutic drug .

\section{MATERIALS AND METHODS}

Cells and Media. U937 (cat. no. CRL-1593.2 ${ }^{\text {TM}}$ ), Raji (cat. no. CCL-86 ${ }^{\mathrm{TM}}$ ) and Namalwa (cat. no. CRL-1432 ${ }^{\mathrm{TM}}$ ) cell lines which were derived from histiocytic lymphoma or Burkitt's lymphoma cells were obtained from A'TCC ${ }^{\circledR}$, USA. Cells were cultured at $37^{\circ} \mathrm{C}$ in a humidified atmosphere $\left(5 \% \mathrm{CO}_{2}\right)$ in the RPMI 1640 medium with $2 \mathrm{mM}$ L-glutamine (Cytogen, Germany), supplemented with $10 \%$ fetal bovine serum (Cytogen, Germany), $1 \mathrm{mM}$ sodium pyruvate, $100 \mathrm{U} / \mathrm{ml}$ penicillin, $100 \mu \mathrm{g} / \mathrm{ml}$ streptomycin. The cell lines were mycoplasma-free as tested by DAPI staining and fluorescence microscopy analysis.

Determination of BITC cytotoxicity towards U937 cells. $1 \times 10^{5}$ cells were seeded in the wells of a 96-well plate, in $100 \mu \mathrm{l}$ of the medium. The cells were treated with different concentrations of BITC $(0-62.5 \mu \mathrm{M})$ for $24 \mathrm{~h} .2 \mathrm{~h}$ before the end of the treatment, $12 \mu \mathrm{l}$ of MTT (Sigma Aldrich, $5 \mathrm{mg} / \mathrm{ml}$ ) were added to all wells. After incubation, the formazan crystals formed by viable cells were dissolved in $110 \mu \mathrm{l}$ of acidic $(40 \mathrm{mM} \mathrm{HCl})$ isopropanol and analysed in a microplate reader at $\lambda=540 \mathrm{~nm}$. Absorbance values of the wells containing treated cells were compared with those of wells with non-treated cells.

Induction of cell death. $1 \times 10^{5}$ of U937 cells per well of a 96-well plate or $3 \times 10^{6}$ of U937, Raji or $\mathrm{Na}$ malwa cells per well of a 6 -well plate were exposed to $25 \mu \mathrm{M}$ BITC (Sigma-Aldrich, 98\% purity) or $50 \mu \mathrm{g} / \mathrm{ml}$ VP-16 (Vepesid ${ }^{\circledR}$, Bristol-Myers Squibb S.p.A., Italy) for up to $24 \mathrm{~h}$, with time range dependent on the type of analysis. After treatment, cells seeded in 6-well plates were used for morphological analysis under Axiovert 200 microscope, with $40 \times$ long distance objective.
Western blot analysis. PARP cleavage, anti- and proapoptotic proteins' expression. After treatment, the cells were harvested and centrifuged $\left(5 \mathrm{~min}, 400 \times g, 4^{\circ} \mathrm{C}\right.$ ). Afterwards, the cells were washed twice with PBS $\times 1$ and suspended in $300 \mu \mathrm{l}$ of Laemmli buffer (SDS 10\%; Tris $0.5 \mathrm{M} \mathrm{pH}$ 6.8; glycerol 20\%). Cell lysates were boiled for $5 \mathrm{~min}$ and cooled on ice for $3 \mathrm{~min}$, with boiling and cooling processes repeated three times. Protein concentration was analysed with the NanoDrop spectrophotometer and standardised in all samples to $1 \mathrm{mg} / \mathrm{ml}$. Samples were mixed with the modified Laemmli buffer (with addition of $\beta$-mercaptoethanol and bromophenol blue) and boiled for $5 \mathrm{~min}$.

Cell lysate was separated on a $4 \%$ (stacking gel) and $12 \%$ (resolving gel) SDS-PAGE under reducing conditions. Resolved proteins were transferred onto a PVDF membrane which was then probed with primary antibodies: monoclonal, rabbit anti-human PARP (Cell Signalling, USA, cat no. 9532, 1:1000 dilution); monoclonal, mouse anti-human Mcl-1 (Santa Cruz Biotechnology, USA, cat. no. sc-12756, 1:200 dilution); monoclonal, mouse anti-human Bcl-2 (BD Transduction Laboratories, USA, cat no. 610538, 1:1000 dilution); monoclonal, mouse anti-human BAG-1 (BD Transduction Laboratories, USA, cat no. 611868, 1:30000 dilution); monoclonal, mouse anti-human PUMA (Cell Signalling, USA, cat no. 4976, 1:1000 dilution); monoclonal, mouse antihuman Bid (BD Transduction Laboratories, USA, cat no. 611528, 1:500 dilution); monoclonal, mouse anti-human Bad (BD Transduction Laboratories, USA, cat no. 610391, 1:1000 dilution); monoclonal, mouse anti-human $\beta$-tubulin (Santa Cruz Biotechnology, USA, cat. no. sc55529, 1:200 dilution).

Affinity purified monoclonal goat anti-mouse $\mathrm{IgG}$ or goat anti-rabbit IgG (Santa Cruz Biotechnology, USA, cat no. sc-2004 and cat no. sc-2005 respectively) conjugated to HRP (horseradish peroxidase 1:2000 dilution) were used as secondary antibodies. BM Chemiluminescence Blotting Substrate (Roche, Switzerland) was used to visualize the protein bands.

Densitometric and statistical analyses for the obtained blots were performed for at least three independent repeats, with the use of Image J v 1.48 (NIH), and Statistica 12.

Flow cytometry analysis. Early apoptosis was evaluated by measuring the exposure of phosphatidylserine on the outer leaflet of plasma membrane. Analysis was performed using FITC-conjugated Annexin-V (FITC Annexin $\mathrm{V}$ Apoptosis Detection Kit, BD Pharmingen ${ }^{\mathrm{TM}}$ ). $1 \times 10^{5}$ BITC-treated cells were washed with $200 \mu \mathrm{l}$ PBS, centrifuged and then suspended in $100 \mu \mathrm{l}$ binding buffer. Afterwards, the cells were incubated for $5 \mathrm{~min}$ at $37^{\circ} \mathrm{C}$ with $5 \mu \mathrm{l}$ of FITC-conjugated Annexin-V and $5 \mu \mathrm{l}$ of propidium iodide. Four subpopulations were identified according to their fluorescence: PI-low/FITC-low (live cells), PI-high/FITC-low (necrotic cells), PI-low/FITChigh (early apoptotic cells), PI-high/FITC-high (late apoptotic cells - confirmed by kinetics of the process).

The mitochondrial membrane potential (MMP) was evaluated using tetramethyl rhodamine methyl ester (TMRM, Fluka). U937 cells were stained with $0.1 \mu \mathrm{M}$ TMRM for $30 \mathrm{~min}$ at $37^{\circ} \mathrm{C}$ before the end of treatment with apoptotic inducers. Afterwards, the cells were centrifuged and suspended in $250 \mu \mathrm{l}$ of fresh RPMI 1640 medium for analysis. Cells with lower mitochondrial potential showed a shift in fluorescence intensity from the control region towards the lower values. All of the measurements were performed for 10000 cells that exhibited a typical forward and side scatter features of non- disas- 
sembled cells. Data were analysed off-line using the BD FACSDiva software (BD Biosciences, USA).

LDH (lactate dehydrogenase) level determination. $1 \times 10^{5}$ cells were treated with $50 \mu \mathrm{g} / \mathrm{ml} \mathrm{VP-16}$ or $25 \mu \mathrm{M}$ BITC for $5 \mathrm{~h}$ and supernatants were collected by centrifugation $(400 \times g, 5 \mathrm{~min})$. Supernatant $(100 \mu \mathrm{l})$ was placed in a 96-well plate and incubated with $100 \mu \mathrm{l}$ of mixed catalyst and Dye Solution (LDH Cytotoxicity Detection Kit, Clontech, USA). Additional controls were performed as follows: medium without cells (absorbance value was subtracted from all controls and samples), non-treated cells' supernatant (low control), and triton X-100 0.1\% treated cells' supernatant (high control). The absorbance was analysed with a microplate reader (450 $\mathrm{nm})$ after $15 \mathrm{~min}$ of incubation.

Determination of cytokine concentration. $1 \times 10^{6}$ of U937 cells were treated with BITC $(25 \mu \mathrm{M})$ or VP-16 $(50 \mu \mathrm{g} / \mathrm{ml})$ for $1.5 \mathrm{~h}$, and then the cells were centrifuged (5 min, $400 \times g$ RT). Pelleted cells were resuspended in the medium devoid of cell death inducers. After $22.5 \mathrm{~h}$ incubation at $37^{\circ} \mathrm{C}$ with $5 \%$ of $\mathrm{CO}_{2}$, the cells were centrifuged. Supernatants were collected and stored at $-70^{\circ} \mathrm{C}$. IL- 8 and MCP-1 levels were assessed in supernatants by enzyme-linked immunosorbent assay using BD OptEIA ${ }^{\mathrm{TM}}$ Human ELISA Kits II (BD Biosciences, USA).

Statistical analysis. Statistical differences between diversely treated U937 cell cultures were determined using the $t$-test and $\mathrm{U}$ Mann-Whitney test after confirming the normal distribution of data. The analyses were performed using 3 to 4 replicate runs in at least three independent experiments. $p$-values $<0.05$ were considered to indicate statistically significant differences.

\section{RESULTS}

\section{Atypical morphology of U937 cells treated with BITC as a cell death inducer}

We analysed morphological changes of U937 cells in response to different concentrations of BITC. According to the literature, an effective concentration of BITC ranges from $0.89 \mu \mathrm{M}$ to $100 \mu \mathrm{M}$ (Lee et al., 2012). Interestingly, for all tested concentrations of BITC, similar morphological changes and a negligible presence of apoptotic bodies were observed (Fig. 1a). Under our experimental conditions an effective BITC concentration which induced a decrease in cell viability after $24 \mathrm{~h}$ treatment was $12 \mu \mathrm{M}$ (Fig. 1b). However, higher concentration of BITC $(25 \mu \mathrm{M})$ was chosen for further investigation in order to assess the final steps of cell death in the majority of cells.

When well-known inducer of apoptosis VP-16 (etoposide) (Jafarlou et al., 2016) was applied at a concentration of $50 \mu \mathrm{g} / \mathrm{ml}$, apoptotic morphological markers and apoptotic bodies were already observed after $3 \mathrm{~h}$ of treatment.

Application of BITC $(25 \mu \mathrm{M})$ for the first $5 \mathrm{~h}$ of treatment did not exert a significant morphological change, in contrast to $3 \mathrm{~h} \mathrm{VP}-16$ treatment (Fig. 1c).

These results indicate that even high concentration of BITC $(62.5 \mu \mathrm{M})$ is not able to cause cell disassembly to apoptotic bodies, although lower BITC concentration, i.e. $12 \mu \mathrm{M}$, causes cell death. Unlike treatment with VP16, BITC did not cause blebbing and disassembly of U937 cells.
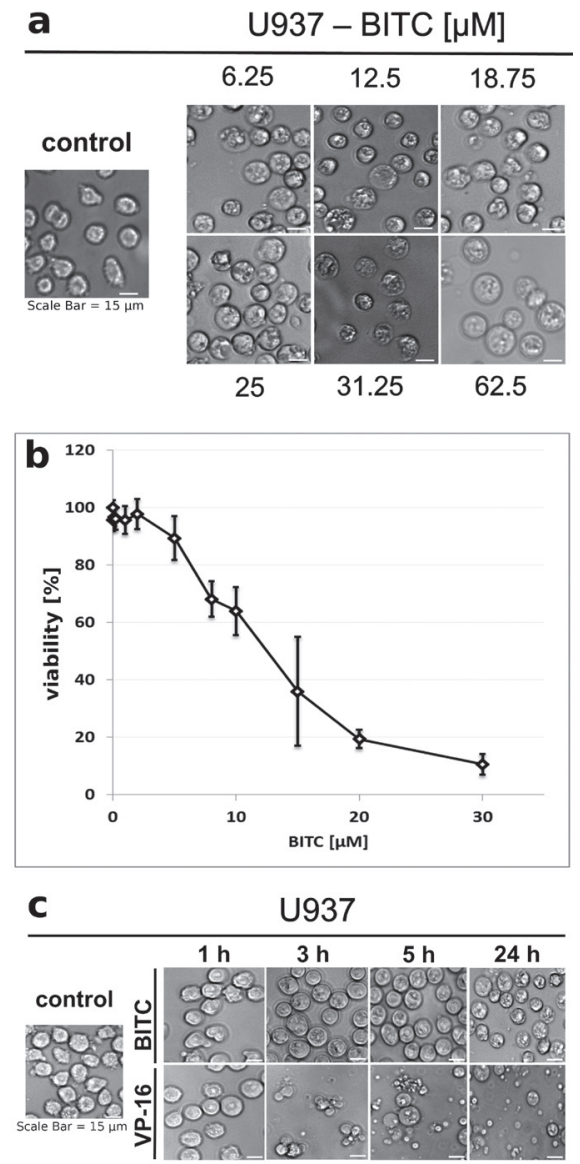

Figure 1. Cytotoxicity of BITC and morphology of the dying U937 cells.

(a) Light microscopy photographs of cells treated with BITC (0$62.5 \mu \mathrm{M}$ ) for $24 \mathrm{~h}$ (40x objective). (b) Viability of U937 cells (MTT assay) after $24 \mathrm{~h}$ treatment with different concentrations of BITC $(0-30 \mu \mathrm{M})$. Results show changes in metabolic activity of cells (in percentage) $\pm S . D$. $(n=4)$. (c) Light microscopy photographs of cells treated with $25 \mu \mathrm{M}$ of BITC or $50 \mu \mathrm{g} / \mathrm{ml} \mathrm{VP-16}$ for $24 \mathrm{~h}$ (40x objective).

\section{Identification of the type of cell death of BITC-treated U937 cells}

BITC was unable to induce morphological markers of apoptosis in dying U937 cells, which remains in discordance with previous reports that suggests that BITC induces this type of cell death (Stasilojc et al., 2013; Wu et al., 2011). Therefore, we decided to analyze other markers of apoptosis as well.

One of the most characteristic markers of the ongoing apoptosis is translocation of phosphatidylserine to the outer leaflet of cell membrane. Presence of phosphatidylserine on BITC-treated U937 cells was analysed with flow cytometry. Simultaneous staining of cells with propidium iodide was used to distinguish necrotic cells. Our results confirmed translocation of phosphatidylserine in BITC-treated cells, however, this process was delayed in comparison to the VP-16-treated cells (Fig. 2a).

Dying U937 cells were characterized by the decreased mitochondrial membrane potential (MMP). The obtained results were similar for both, the BITC- and VP16-treated U937 cells (Fig. 2b).

To define if the observed cell death mechanism is caspase-dependent, presence of cleaved PARP in cell lysates was evaluated. Cleaved form of PARP was pre- 

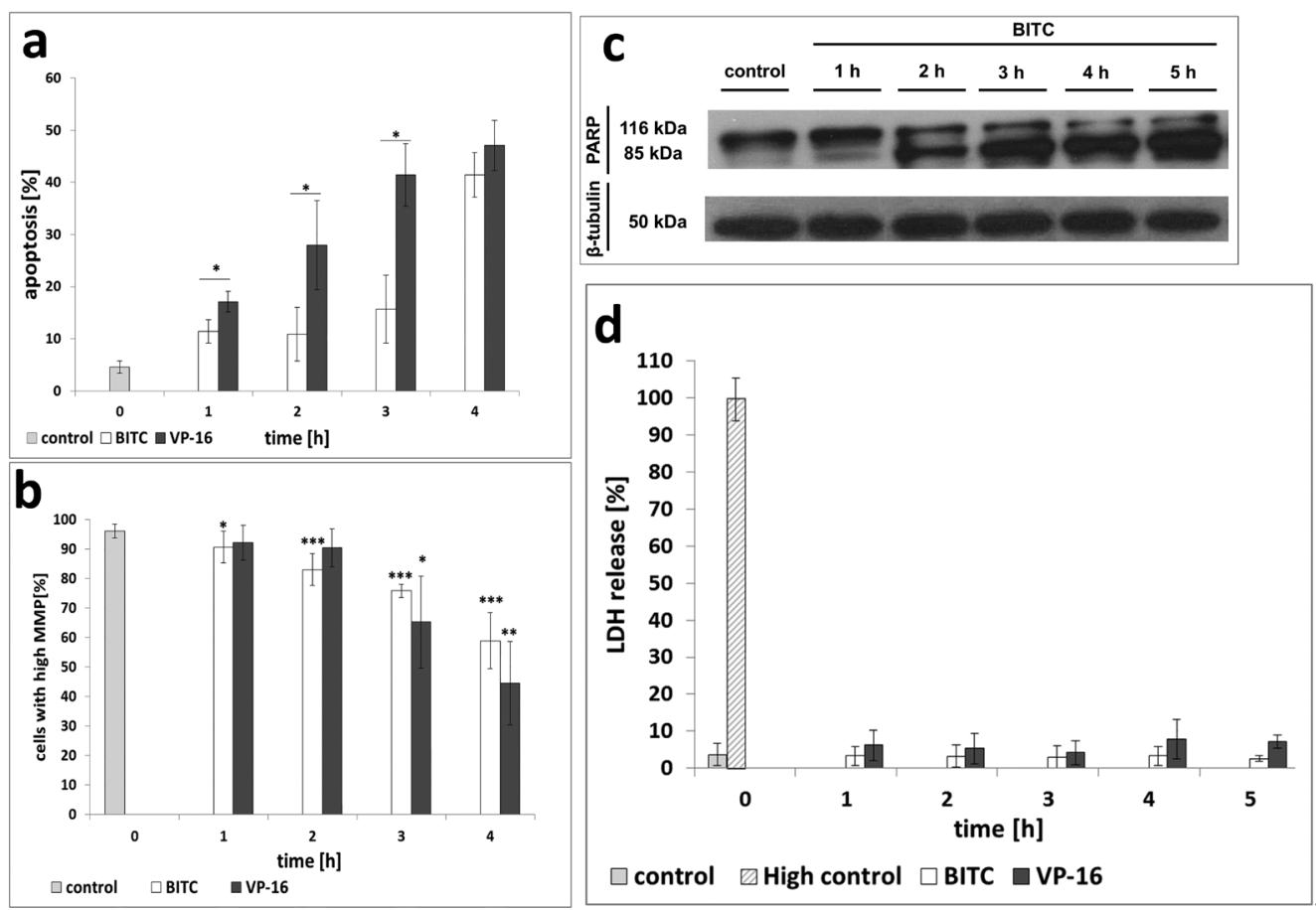

Figure 2. Apoptotic features of U937 cell death.

(a) Phosphatidylserine presence on the outer leaflet of cell membrane of U937 cells treated with $25 \mu \mathrm{M} \mathrm{BITC} \mathrm{or} 50 \mu \mathrm{g} / \mathrm{ml}$ VP-16 for 0-4 h. Cells analysed by flow cytometry after annexin-V-FITC and propidium iodide staining. Results show the mean number of cells with positive FITC signal (in percentage of all analysed cells) \pm S.D. $(n=4)$. Statistically significant differences between cells treated with BITC and VP-16 are indicated $\left.{ }^{*} p<0.05\right)$. (b) Mitochondrial membrane potential (MMP). Cytometric analysis of MMP with TMRM in cells treated with $25 \mu \mathrm{M} \mathrm{BITC}$ or $50 \mu \mathrm{g} / \mathrm{ml}$ VP-16 for $4 \mathrm{~h}$. Results represent the mean number of cells with high MMP (high TMRM - considered as the level of fluorescence for control cells) \pm S.D. ( $n=4)$. Statistically significant differences between U937 cells treated with BITC or VP-16 and control are indicated $\left({ }^{*} p<0.05,{ }^{* *} p<0.01,{ }^{* * *} p<0.005\right)$. (c) PARP cleavage. U937 cells treated with $25 \mu \mathrm{M}$ BITC for $0-5$ h. Cytosolic fractions of cell lysates were prepared and subjected to western blot analysis using antibodies against PARP. Presence of $116 \mathrm{kDa}$ PARP protein and one of its cleaved fragments, $85 \mathrm{kDa}$ CF (catalytic fragment) were visualised. $\beta$-tubulin was used as a protein quantity marker. (d) $\mathrm{LDH}$ release. Cells were treated with $25 \mu \mathrm{M}$ BITC or $50 \mu \mathrm{g} / \mathrm{ml} \mathrm{VP-16}$ for $0-5 \mathrm{~h}$. The cell supernatants were obtained and analysed in colorimetric test for the presence of cytoplasmic LDH (lactate dehydrogenase). Results show the mean value of LDH activity as percentage \pm S.D. $(n=5)$ of maximal absorbance control (high control). High absorbance indicates a presence of cells with discontinuous cell membrane. Control - U937 cells without cell death inducer; high control - U937 cells in the medium containing $0.1 \%$ of Triton X-100.

sent in cell lysates after $2 \mathrm{~h}$ of treatment and its amount increased in a time dependent manner (Fig. 2c).

Additionally, we looked for a possible necrotic component of the observed cell death (Miyoshi et al., 2008). The level of lactate dehydrogenase (LDH) released from cytosol was assessed in supernatants of cells treated with BITC or VP-16 for $5 \mathrm{~h}$. Activities of LDH in the supernatants of treated and untreated cells were compared. The results showed a similar, low level of $\mathrm{LDH}$ release for both tested cell death inducers, which indicated a lack of rapid necrosis (Fig. 2d).

In summary, U937 cells treated with BITC exhibit most of the characteristics of caspase-dependent apoptotic cell death, similar to those observed for the U937 cells treated with VP-16, except for disassembly to apoptotic bodies which is a morphological marker of late apoptosis.

\section{BITC-treatment does not affect $\mathrm{Bcl}-2, \mathrm{Mcl}-1$, Bid and Bad protein levels, but affects PUMA and BAG-1 in the U937 cells}

The main regulators of apoptosis are the Bcl-2 family of pro- and anti-apoptotic proteins. A dependence between the level of myeloid cell leukemia-1 (Mcl-1 BCL2 Family Apoptosis Regulator) and BITC-induced apoptosis was suggested (Jafarlou et al., 2016; Zhou et al., 2013). During the first $12 \mathrm{~h}$ of BITC treatment, no statistically relevant changes in the Mcl-1 level were found in the U937 cells. Similar result was obtained for major anti-apoptotic protein Bcl-2. However, we observed a statistically significant increase in the levels of large and medium isoforms of BAG-1 (BCL2-associated athanogene) during the first 6 hours of treatment. BAG-1 small isoform showed a distinct trend towards significance $(p<0.07)$ after $12 \mathrm{~h}$ of BITC-treatment (Fig. 3). Densitometric analysis is shown in the supplementary data.

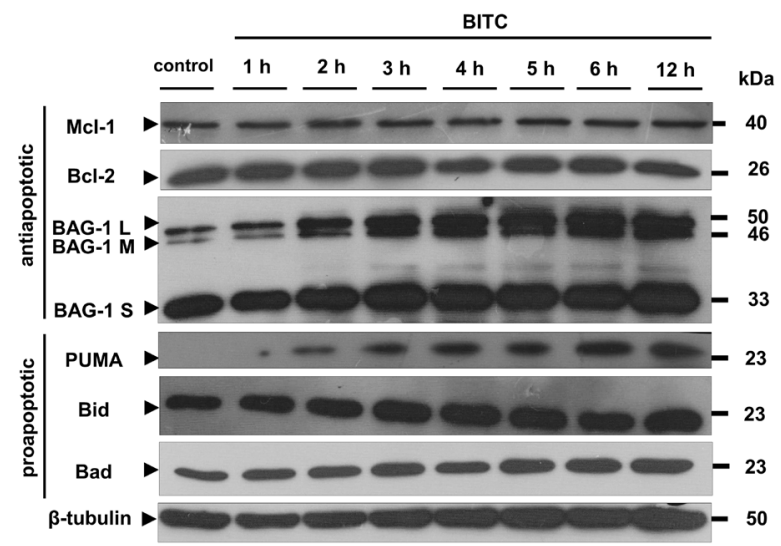

Figure 3. Level of pro- and anti-apoptotic proteins in cell lysates.

Lysates were obtained from U937 cells treated with $25 \mu \mathrm{M}$ BITC for $0-6$ and $12 \mathrm{~h}$. The expression of Mcl-1, BCl-2, BAG-1, PUMA, Bid, Bad was analysed with Western blot. $\beta$-tubulin was used as a protein quantity marker. 


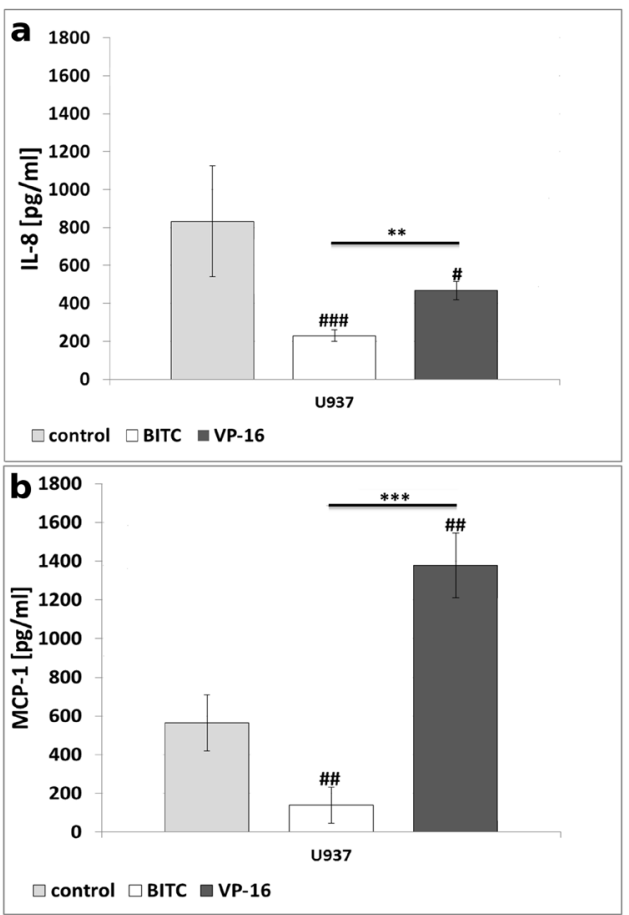

Figure 4. Cytokine release by dying U937 cells.

U937 cells were induced to die with $25 \mu \mathrm{M}$ of BITC or VP-16 (50 $\mu \mathrm{g} / \mathrm{ml}$ ) for $1.5 \mathrm{~h}$ followed by a change of medium. The cell supernatants were obtained after $24 \mathrm{~h}$ and analysed by ELISA test. (a) IL-8 concentration. (b) MCP-1 concentration. Results represent the concentration of cytokines $(\mathrm{pg} / \mathrm{ml})$ in the supernatants \pm S.D. $(n=3)$. Statistically significant differences between U937 cells treated with BITC or VP-16 indicated $\left({ }^{* *} p<0.01\right.$, $\left.{ }^{* * *} p<0.005\right)$, between inducer-treated cells and untreated cells indicated $(\# p<0.5$,

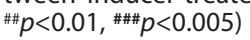

Increased expression of the PUMA protein (p53 upregulated modulator of apoptosis) in adherent cell lines treated with BITC was indicated in the literature (Antony et al., 2012) and our results remain in accordance with that report. A significant increase in the PUMA level was observed during BITC-treatment, whereas the Bid and Bad protein levels did not changed during the first $12 \mathrm{~h}$ of treatment (Fig. 3).

\section{Release of chemotactic cytokines}

IL-8 and MCP-1 are two of the most important proinflammatory chemokines ( $\mathrm{Hu}$ et al., 2014). MCP-1 recruits monocytes into the foci of active inflammation and it is associated with the development of Th2-polarized response (Deshmane et al., 2009). Supernatants collected from BITC- or VP-16-treated cells (24 h) were used to determine the level of IL-8 and MCP-1.

Unlike the control and VP-16-treated cells, BITCtreated U937 cells secreted a significantly lower level of IL-8 and MCP-1 (Fig. 4a and Fig. 4b). Thus, it should be emphasized that BITC-treated U937 cells, which did not disassemble during the death process, secrete lower levels of chemotactic cytokines.

\section{Presence of that unusual cell death morphology in other cell lines}

Raji and Namalwa cells were treated with BITC $(25 \mu \mathrm{M})$ or VP-16 $(50 \mu \mathrm{g} / \mathrm{ml})$ for $24 \mathrm{~h}$. Those cells did show similar morphological changes to those of BITCtreated U937 cells (Fig. 5). However, morphological dif-

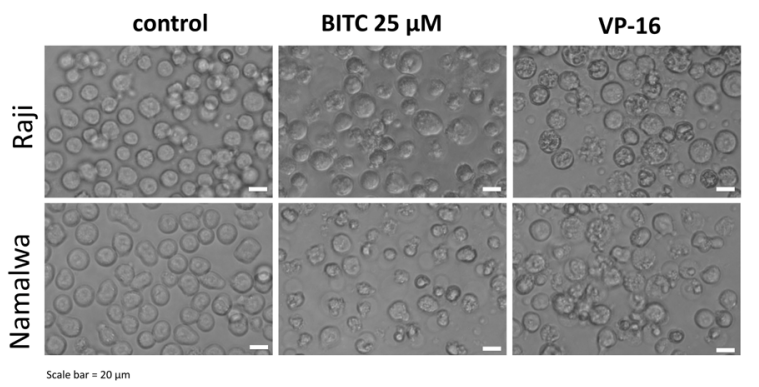

Figure 5. Morphology of dying Raji, Namalwa and Ramos cells. Light microscopy photographs of cells treated with BITC $(25 \mu \mathrm{M})$ or VP-16 $(50 \mu \mathrm{g} / \mathrm{ml})$ for $24 \mathrm{~h}$ (40x objective).

ferences between cells treated with BITC and VP-16 were not as evident as for the U937 cells.

\section{DISCUSSION}

Few reports describe cell death of human or murine leukemia cells (Jurkat, HL-60, WEHI-3) treated with BITC (Antony et al., 2012; Coleman et al., 2001; Lee et al., 2009; Zhou et al., 2013). In the study presented here we chose U937 cells as an acknowledged model for a standard caspase-dependent apoptosis (Stasilojc et al., 2013). Our results remain in accordance with previous reports of BITC cytotoxic effects on leukemia cells (Zhang et al., 2003), but indicate that the observed morphological and biochemical markers are not typical for standard apoptotic cell death (Fadok et al., 1992). Pharmacokinetic data for BITC in the human serum is currently unavailable. However, in vivo concentrations of BITC used in animal studies are several orders of magnitude higher (e.g. $10 \mathrm{mg} / \mathrm{kg}$ equal to $50 \mu \mathrm{M}$ ) than dietary consumption in humans (Kassie et al., 1999). In our cell model (U937) $25 \mu \mathrm{M}$ of BITC was close to IC90, so it was possible to observe and describe changes induced by BITC in a late stage of the apoptosis process.

One of our main goals was to observe morphological effects of BITC on U937. Negligible cell disassembly, but noticeable granularity of the dying cells were observed. These morphological markers were different in comparison to leukemia cells treated with other death inducers (Stasilojc et al., 2013). Similar morphological changes as BITC-treated U937 cells were observed for Raji and Namalwa cell lines. However, morphological differences of BITC- or VP-16-treated cells were not as evident as for the U937 cells.

Increased activity of caspases followed by cleavage of PARP (Fig. 2c), phosphatidylserine translocation (Fig. 2a) and decrease in mitochondrial membrane potential (MMP) (Fig. 2b) observed in BITC-treated U937 cells are consistent with literature description of apoptosis (Miyoshi et al., 2008; Wu et al., 2011; Xiao et al., 2006). We did not confirm the presence of a necrotic component of cell death during the first five hours after cell death induction (Fig. 2d), although such an observation was described in the literature (Miyoshi et al., 2008). Presence of secondary necrosis was negligible, as the average ratio of early apoptosis versus late apoptosis was 47.2 ( \pm 14.3 ). Therefore, cell death induced by BITC in U937 seems to demonstrate the main molecular markers of caspase-dependent apoptosis. However, the lack of apoptotic bodies formation indicates an atypical process of apoptosis. 


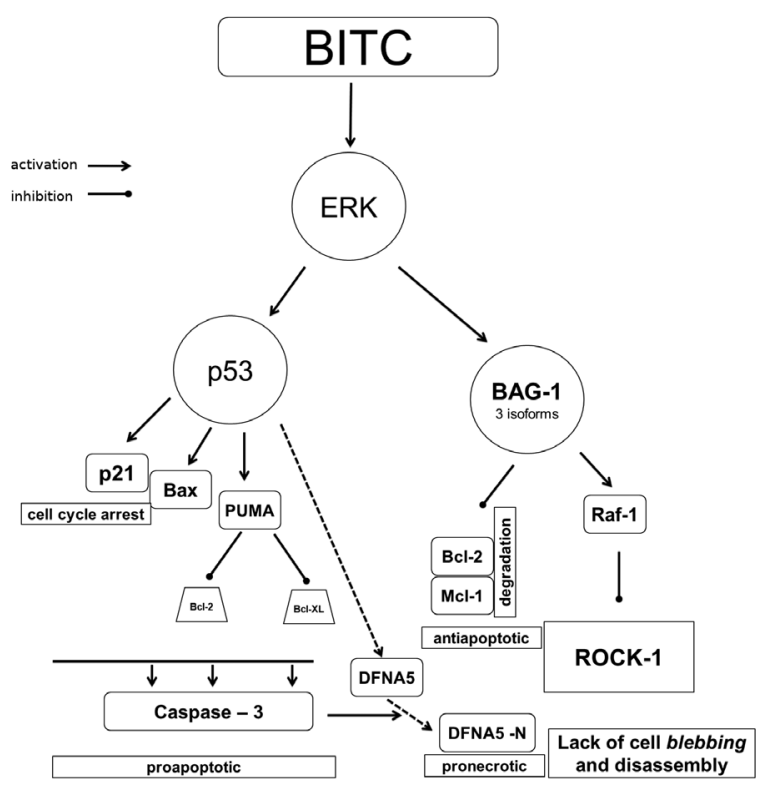

Figure 6. A proposed mechanism for the benzyl isothiocyanate (BITC)-induced U937 apoptosis with no blebbing and disassembly to apoptotic bodies.

Literature data describe BITC-induced molecular markers associated with cell death e.g. Mcl-1 or Bax downregulation, using different cell lines (Xiao et al., 2006; Zhou et al., 2013). However, our results with the U937 cells show differences with respect to these proteins. Moreover, there are reports presenting a critical role of pro-apoptotic PUMA protein in the BITC-dependent apoptosis (Antony et al., 2012). Our observations confirm the involvement of PUMA and also of the BAG-1 isoforms in the U937 model. BITC increases phosphorylation of extracellular signal-regulated kinase (ERK) (Xie et al., 2017). BAG-1 is up-regulated in a MAPK/ERKdependent fashion (Li et al., 2015). Overexpression of Mcl-1, an anti-apoptotic Bcl-2 family member protein, is associated with tumor progression and drug resistance in leukemia and several cancers (Wu et al., 2011). Literature data also indicate that apoptosis of BITC-treated leukemia cells may depend on translational downregulation of Mcl-1 (Zhou et al., 2013). Notably, the role of Mcl-1 in the death process of BITC-treated U937 cells was not indicated by our results. BAG-1 upregulation is considered as an important biomarker of increased cell survival capacities. It is also co-involved in delayed cell apoptosis activation by protection of $\mathrm{Bcl} 2$ and $\mathrm{Mcl}-1$ proteins from degradation (Aveic et al., 2015). Insignificant changes in the $\mathrm{Mcl}-1$ and $\mathrm{Bcl} 2$ levels may be the results of high BAG-1 level during BITC-induced cell death. On the other hand, they may also clarify unusual apoptosis activation and progression.

Disassembly of cells to apoptotic bodies followed by their clearance (efferocytosis) is one of the most important events for the immune system (Grabiec \& Hussell, 2016). Membrane blebs function as chemoattractants, recruiting monocytes to the sites of apoptosis (Segundo et al., 1999). The DFNA5 protein is considered as a central regulatory protein for disassembly and progression of apoptotic cells to secondary necrosis (Rogers et al., 2017). We do not exclude participation of DFNA5 cleavage form in the analysed mechanism, however, the insignificant level of secondary necrosis in U937 cells in the first key time points of BITC induction suggests that its role in that mechanism may be negligible.

ROCK (Rho-associated protein kinase) plays a key role in actin-myosin contraction in bleb production. ROCK inhibition significantly reduces apoptotic body formation and apoptotic cell phagocytosis (Wickman et al., 2013). Raf-1 kinase is able to reduce activity of ROCK (Matsubara \& Bissell, 2016), but Raf-1 ability to inhibit ROCK depends on BAG-1 (Planchamp et al., 2008). Our results showed increasing levels of BAG-1 isoforms. That result may provide a novel mechanism to explain the lack of BITC-treated U937 cell blebbing and disassembly to apoptotic bodies (Fig. 6).

Higher number of non-disassembled apoptotic cell remains could possibly influence the efficiency of the clearance process. Weakened efferocytosis may cause secondary necrosis of the cell debris (Rogers et al., 2017). That process is followed by release of intracellular contents, including damage-associated molecular patterns (DAMPs), resulting in an inflammatory response of the innate immune system (Grabiec \& Hussell, 2016; Rogers et al., 2017; Wickman et al., 2013).

An anti-inflammatory effect of BITC was shown with mouse cells and tissues (Lee et al., 2009). Our study indicates low levels of chemoattractants (IL-8 and MCP-1) in cell supernatants. Therefore, inadequate chemoattraction of macrophages, neutrophils and human $\mathrm{T}$ lymphocytes towards dying U937 cells may take place (de Boer et al., 2000).

\section{CONCLUSIONS}

The BITC-treated cells were characterized by major morphological and biochemical markers of apoptosis. The imbalance between pro- and antiapoptotic proteins may influence disassembly into the apoptotic bodies. Relationship between proapoptotic PUMA and antiapoptotic BAG-1, influenced by other proteins such a Raf-1, could affect bleb formation and lack of disassembly to apoptotic bodies.

Low levels of chemokines may contribute to reduced chemotaxis of macrophages and other immune cells. Therefore, it may affect their ability to remove remnants of the dying BITC-treated U937 cells. The size of remnants and potentially lower number of recruited phagocytes may result in secondary necrosis of the dying cells in vivo. Tumor cells are able to suppress immune response in vivo (Munn \& Bronte, 2016) and this effect may also be relevant in case of leukemias (Bakker et al., 2016). Importantly, release of intracellular contents, including DAMPs, followed by an inflammatory response may disrupt immunosuppressive potential of the tumor cells.

Regulation of disassembly to apoptotic bodies of BITC-treated cells should be further analysed. It should cover caspase activity during that process, confirmation of ROCK involvement by using siRNA to knock it down at different time points, and finally verification of the clearance process using macrophages (e.g. THP-1) in vitro.

Analysis of BITC in clinical trials should also take under consideration the combined effect of defective apoptosis and decreased expression of pro-inflammatory cytokines in the tumour cells on its chemopreventive role in vivo. We also conclude that BITC inclusion in anticancer therapies may affect the proinflammatory effect for various cancer cell types that exhibit the same 
BITC-induced apoptosis mechanism as was shown for the U937 cells.

\section{Conflict of interest}

We declare no conflict of interest.

\section{REFERENCES}

Antony ML, Kim SH, Singh SV (2012) Critical role of p53 upregulated modulator of apoptosis in benzyl isothiocyanate-induced apoptotic cell death. PLoS One 7: e32267. https://doi.org/10.1371/journal. pone.0032267

Aveic S, Viola G, Accordi B, Micalizzi C, Santoro N, Masetti R, Locatelli F, Basso G, Pigazzi M (2015) Targeting BAG-1: a novel strategy to increase drug efficacy in acute myeloid leukemia. Exp Hematol 43: 180-190. e186. https://doi.org/10.1016/j.exphem.2014.10.016

Bakker E, Qattan M, Mutti L, Demonacos C, Krstic-Demonacos M (2016) The role of microenvironment and immunity in drug response in leukemia. Biochim Biophys Acta 1863: 414-426. https://doi. org/10.1016/j.bbamcr.2015.08.003

Coleman ML, Sahai EA, Yeo M, Bosch M, Dewar A, Olson MF (2001) Membrane blebbing during apoptosis results from caspasemediated activation of ROCK I. Nat Cell Biol 3: 339-345. https:// doi.org/10.1038/35070009

de Boer WI, Sont JK, van Schadewijk A, Stolk J, van Krieken JH, Hiemstra PS (2000) Monocyte chemoattractant protein 1 interleukin 8 and chronic airways inflammation in COPD. J Pathol 190: 619-626. https://doi.org/10.1002/(SICI)1096-9896(200004)190:5<619::AIDPATH555>3.0.CO;2-6

Deshmane SL, Kremlev S, Amini S, Sawaya BE (2009) Monocyte chemoattractant protein-1 (MCP-1): an overview. I Interferon Cytokine Res 29: 313-326. https://doi.org/10.1089/jir.2008.0027

Fadok VA, Voelker DR, Campbell PA, Cohen JJ, Bratton DL, Henson PM (1992) Exposure of phosphatidylserine on the surface of apoptotic lymphocytes triggers specific recognition and removal by macrophages. I Immunol 148: 2207-2216

Grabiec AM, Hussell T (2016) The role of airway macrophages in apoptotic cell clearance following acute and chronic lung inflammation. Semin Immunopathol. https://doi.org/10.1007/s00281-016-05553

Hu DN, Bi M, Zhang DY, Ye F, McCormick SA, Chan CC (2014) Constitutive and LPS-induced expression of MCP-1 and IL-8 by human uveal melanocytes in vitro and relevant signal pathways. Invest Ophthalmol Vis Sci 55: 5760-5769. https://doi.org/10.1167/ iovs.14-14685

Jafarlou M, Baradaran B, Shanehbandi D, Saedi TA, Jafarlou V, Karimi P, Othman F (2016) Silencing of myeloid cell leukemia-1 by small interfering RNA improves chemosensitivity to etoposide in u-937 leukemic cells. I Biol Regul Homeost Agents 30: 55-65

Kassie F, Pool-Zobel B, Parzefall W, Knasmuller S (1999) Genotoxic effects of benzyl isothiocyanate a natural chemopreventive agent Mutagenesis 14: 595-604. https://doi.org/10.1093/mutage/14.6.595

Keum YS, Jeong WS, Kong AN (2004) Chemoprevention by isothiocyanates and their underlying molecular signaling mechanisms. Mutat Res 555: 191-202. https://doi.org/10.1016/j.mrfmmm.2004.05.024

Kim SH, Singh SV (2015) The role of polycomb group protein Bmi1 and Notch4 in breast cancer stem cell inhibition by benzyl isothiocyanate. Breast Cancer Res Treat 149: 681-692. https://doi. org/10.1007/s10549-015-3279-5

Lee Y, Kim YJ, Choi YJ, Lee JW, Lee S, Chung HW (2012) Enhancement of cisplatin cytotoxicity by benzyl isothiocyanate in HL-60 cells. Food Chem Toxicol 50: 2397-2406. https://doi.org/10.1016/j. fct.2012.04.014

Lee YM, Seon MR, Cho HJ, Kim JS, Park JH (2009) Benzyl isothiocyanate exhibits anti-inflammatory effects in murine macrophages and in mouse skin. J Mol Med (Berl) 87: 1251-1261. https://doi. org/10.1007/s00109-009-0532-6

Li HP, Yuan CL, Zho YC (2015) Human cytomegalovirus inhibits apoptosis involving upregulation of the antiapoptotic protein Bag-1.J Med Virol 87: 1953-1959. https://doi.org/10.1002/imv.24259

Liu BN, Yan HQ, Wu X, Pan ZH, Zhu Y, Meng ZW, Zhou QH, Xu $\mathrm{K}$ (2013) Apoptosis induced by benzyl isothiocyanate in gefitinibresistant lung cancer cells is associated with Akt/MAPK pathways and generation of reactive oxygen species. Cell Biochem Biophys 66 : 81-92. https://doi.org/10.1007/s12013-012-9456-9

Matsubara M, Bissell MJ (2016) Inhibitors of Rho kinase (ROCK) signaling revert the malignant phenotype of breast cancer cells in
3D context. Oncotarget 7: 31602-31622. https://doi.org/10.18632/ oncotarget.9395

Miyoshi N, Watanabe E, Osawa T, Okuhira M, Murata Y, Ohshima H, Nakamura Y (2008) ATP depletion alters the mode of cell death induced by benzyl isothiocyanate. Biochim Biophys Acta 1782: 566-573. https://doi.org/10.1016/j.bbadis.2008.07.002

Miyoshi N, Yonemochi T, Tomono S, Fukutomi R, Nakamura Y, Ohshima H (2012) Development and application of a method for identification of isothiocyanate-targeted molecules in colon cancer cells. Anal Biochem 429: 124-131. https://doi.org/10.1016/j. ab.2012.07.018

Munn DH, Bronte V (2016) Immune suppressive mechanisms in the tumor microenvironment. Curr Opin Immunol 39: 1-6. https://doi. org/10.1016/j.coi.2015.10.009

Negroni A, Cucchiara S, Stronati L (2015) Apoptosis necrosis and necroptosis in the gut and intestinal homeostasis. Mediators Inflamm 2015: 250762. https://doi.org/10.1155/2015/250762

Planchamp V, Bermel C, Tonges L, Ostendorf T, Kugler S, Reed JC, Kermer P, Bahr M, Lingor P (2008) BAG1 promotes axonal outgrowth and regeneration in vivo via Raf-1 and reduction of ROCK activity. Brain 131: 2606-2619. https://doi.org/10.1093/brain/ awn196

Python F, Goebel C, Aeby P (2007) Assessment of the U937 cell line for the detection of contact allergens. Toxicol Appl Pharmacol 220: 113-124. https://doi.org/10.1016/j.taap.2006.12.026

Rao CV (2013) Benzyl isothiocyanate: double trouble for breast cancer cells. Cancer Prev Res (Phila) 6: 760-763. https://doi. org/10.1158/1940-6207.CAPR-13-0242

Rogers C, Fernandes-Alnemri T, Mayes L, Alnemri D, Cingolani G, Alnemri ES (2017) Cleavage of DFNA5 by caspase-3 during apoptosis mediates progression to secondary necrotic/pyroptotic cell death. Nat Commun 8: 14128. https://doi.org/10.1038/ ncomms14128

Segundo C, Medina F, Rodriguez C, Martinez-Palencia R, Leyva-Cobian F, Brieva JA (1999) Surface molecule loss and bleb formation by human germinal center B cells undergoing apoptosis: role of apoptotic blebs in monocyte chemotaxis. Blood 94: 1012-1020

Stasilojc G, Pinto S, Wyszkowska R, Wejda M, Slominska EM, Filipska M, Koszalka P, Swierczynski J, O’Connor JE, Bigda JJ (2013) U937 variant cells as a model of apoptosis without cell disintegration. Cell Mol Biol Lett 18: 249-262. https://doi.org/10.2478/s11658-0130087-y

Toda S, Nishi C, Yanagihashi Y, Segawa K, Nagata S (2015) Clearance of apoptotic cells and pyrenocytes. Curr Top Dev Biol 114: 267-295. https://doi.org/10.1016/bs.ctdb.2015.07.017

Wickman GR, Julian L, Mardilovich K, Schumacher S, Munro J, Rath N, Zander SA, Mleczak A, Sumpton D, Morrice N, Bienvenut WV, Olson MF (2013) Blebs produced by actin-myosin contraction during apoptosis release damage-associated molecular pattern proteins before secondary necrosis occurs. Cell Death Differ 20: 1293-1305. https://doi.org/10.1038/cdd.2013.69

Wu CL, Huang AC, Yang JS, Liao CL, Lu HF, Chou ST, Ma CY, Hsia TC, Ko YC, Chung JG (2011) Benzyl isothiocyanate (BITC) and phenethyl isothiocyanate (PEITC)-mediated generation of reactive oxygen species causes cell cycle arrest and induces apoptosis via activation of caspase- 3 mitochondria dysfunction and nitric oxide (NO) in human osteogenic sarcoma U-2 OS cells. J Orthop Res 29: 1199-1209. https://doi.org/10.1002/jor.21350

Xiao D, Vogel V, Singh SV (2006) Benzyl isothiocyanate-induced apoptosis in human breast cancer cells is initiated by reactive oxygen species and regulated by Bax and Bak. Mol Cancer Ther 5: 29312945. https://doi.org/10.1158/1535-7163.MCT-06-0396

Xie B, Nagalingam A, Kuppusamy P, Muniraj N, Langford P, Gyorffy B, Saxena NK, Sharma D (2017) Benzyl Isothiocyanate potentiates p53 signaling and antitumor effects against breast cancer through activation of p53-LKB1 and p73-LKB1 axes. Sci Rep 7: 40070. https://doi.org/10.1038/srep40070

Zhang Y, Chen X, Gueydan C, Han J (2018) Plasma membrane changes during programmed cell deaths. Cell Res 28: 9-21. https://doi. org/10.1038/cr.2017.133

Zhang Y, Tang L, Gonzalez V (2003) Selected isothiocyanates rapidly induce growth inhibition of cancer cells. Mol Cancer Ther 2: 10451052

Zhou T, Li G, Cao B, Liu L, Cheng Q, Kong H, Shan C, Huang X, Chen J, Gao N (2013) Downregulation of Mcl-1 through inhibition of translation contributes to benzyl isothiocyanate-induced cell cycle arrest and apoptosis in human leukemia cells. Cell Death Dis 4: e515. https://doi.org/10.1038/cddis.2013.41 